JOAN H. GEISMAR

META F. JANOWITZ

\section{Health, Sanitation, and Foodways in Historical Archaeology: Introduction}

Health, sanitation, and subsistence in one form or another have been among the concerns of archaeologists since the discipline's early years. The six articles presented here deal with these matters from various historical and archaeological perspectives. All are revised and expanded versions of papers given at the First Joint Archaeological Conference in Baltimore in 1989, in the symposium titled "Diet, Health, and Sanitation: An Urban Perspective." Each contribution offers some aspect of an interdisciplinary approach to issues in historical archaeology. Although some of the articles deal with food and household management, arenas usually associated with women's issues, here they are not gender specific. Moreover, most of the essays are data-rich, utilizing archaeological material as well as various forms of documentation and analysis.

The articles are organized so that a commentary by John Duffy, a scholar who specializes in the history of public health in the United States, appears first. Duffy presents a brief description of each article with his assessment of its contribution from a non-archaeologist's point of view. His vantage point illustrates that an interdisciplinary approach to historical archaeology not only derives information from other disciplines, but, not at all surprisingly, it also contributes to them. Following Duffy's commentary and the six substantive articles is a detailed evaluation by Stephen Mro- zowski, an archaeologist. His concluding discourse is based on interpretations of current archaeological theory.

The articles themselves reflect the interests and approaches of the individual authors. No attempt has been made, here or in the original symposium, to structure them according to any particular theoretical focus. Instead, each writer chose and developed her theme under the rubric of the symposium title. This flexibility has resulted in a broad approach to the daily concerns of those whose lives were exposed through documentary and archaeological scrutiny (see Janowitz, Geismar, Rothschild and Balkwill, and Beaudry). Changing attitudes toward health and foods during the 19th century are examined by a food historian (Ross). Olive Jones provides indispensable "tools" with which to interpret archaeological data.

As a collection, these articles illustrate what can be achieved using the diverse resources available to the historical archaeologist. Indeed, they indicate that it may not be data or theory that are wanting, but that the issues may need to be more complex. In other words, one must strive to realize the full potential of what one already has: the sites; the artifacts; the documents; the pictures; the historical interpretations; and the floral, faunal, parasitological, and chemical analyses. In the evolutionary course of the discipline, this approach may prove to be among the more viable options for interpreting life in the past. 